\title{
Palavras que viajam com a cidadania: promoção da educação para o
}

\section{desenvolvimento}

\section{Words traveling to citizenship: promoting education for development}

\author{
Sanches, Angelina*; Mesquita, Elza*; Freire-Ribeiro, Ilda*;\&Bergano, Sofia** \\ *Departamento de Supervisão da Prática Pedagógica, Escola Superior de Educação do Instituto Politécnico de Bragança - Portugal. \\ **Departamento de Ciências da Educação, Escola Superior de Educação do Instituto Politécnico de Bragança - Portugal.
}

\begin{abstract}
Resumo
Este trabalho procura aprofundar a problemática que envolve a construção de práticas de cidadania no quadro da educação para o desenvolvimento. Pretende-se, através da implementação de um projeto que envolve formandos dos cursos de mestrado, construir materiais didático-pedagógicos para crianças dos 3 aos 12 anos. O projeto desenvolve-se em 6 fases, que se iniciam com a formação dos futuros professores/educadores e terminam com a apresentação pública dos resultados alcançados, sendo que cada uma destas fases será avaliada com recurso a metodologias diversas. Espera-se que da implementação do projeto resultem aprendizagens (trans)formadoras no âmbito da promoção da educação para o desenvolvimento. Palavras-chave: cidadania, materiais pedagógicos, educação, desenvolvimento
\end{abstract}

\begin{abstract}
This work seeks to deepen the problem involving the construction of citizenship practices in the context of education for development. It is intended, through the implementation of a project involving graduates of master's courses, build didactic and pedagogic materials for children from 3 to 12 years. The project is developed in six phases, beginning with the training of future teachers / educators and end with a public presentation of the results achieved, and each of these phases will be evaluated with the use of different methodologies. It is expected that the implementation of the project resulting learning (trans) forming in the promotion of education for development. Keywords: citizenship, teaching materials, education, development
\end{abstract}

\section{Cidadania, educação e desenvolvimento}

O ano de 2015, por decisão do Parlamento e do Conselho Europeu, é o "Ano Europeu para o Desenvolvimento", com o lema "O nosso mundo, a nossa dignidade, o nosso futuro”. Nesta linha regista-se a Educação para o Desenvolvimento (ED) que se constitui como um processo educativo, dinâmico e participativo. O conceito de ED, com um caráter globalizador, propõe a conjugação de três princípios básicos: (i) conservar a diversidade da base de recursos naturais e culturais, (ii) manter a qualidade do planeta e, (iii) garantir aos seus membros o acesso a condições de igualdade de direitos (Weis, 1989, cit. in Rayo, 2004).

A ED nasceu na década de 70 do século XX e o seu conceito, devido ao seu percurso e contributos nacionais e internacionais, foi alvo de transformações e delimitações que foram construindo diferentes enfoques da ED. É atualmente um "conceito centrado na pessoa” (Rayo, 2004, p.142) e que, segundo a Estratégia Nacional de Educação para o Desenvolvimento 2010-2015 (ENED, 2008) se traduz na consciencialização e sensibilização sobre os problemas de desenvolvimento, na adoção de atitudes e estratégias favoráveis a uma coesão social e no envolvimento de todos no sentido da transformação social. O cerne da ED é a opinião pública, da qual todos fazemos parte. O principal objetivo é torná-la capaz de refletir e de agir no sentido da alteração de situações que provocam desequilíbrios e injustiças a nível individual e coletivo. Desta forma a ED apela à reflexão e à ação sobre os problemas sentidos por cada um e pela sociedade, na interação, na tomada de consciência, cuja evolução acompanha as dinâmicas de intervenção e transformação social.

Em traços gerais, a ED envolve três dimensões: sensibilizar, consciencializar e influenciar as políticas (ENED, 2008). Ao sensibilizar as pessoas sobre as situações de vida está a dar-se a oportunidade dos cidadãos se questionarem acerca da justiça e injustiça fazendo com que exista a vontade de mudar o que de alguma forma é injusto. A consciencialização dos seus limites, da sua própria condição e também das outras pessoas, ajuda à avaliação destas situações e à proposta de estratégias e projetos de mudança e transformação tendo por base critérios de justiça e solidariedade. Ao influenciar as políticas, dimensão mais ambiciosa, denunciam-se situações que contribuem para a perpetuação de desigualdades sociais e promove-se o bem comum à escala local e global (ENED, 2008).

A ED, por um lado, enquanto educação para a mudança assume diferentes dimensões e pode incluir-se no desenvolvimento de temáticas específicas e diversas de "educação para...", como é o caso de: educação para os direitos humanos; educação ambiental/desenvolvimento sustentável; educação para a igualdade de género; educação intercultural; educação para a paz; educação para a cidadania global; educação para aprender a viver juntos, entre outras. Por outro lado, e segundo o documento oficial sobre as linhas orientadoras de Educação para a Cidadania da Direção Geral da Educação (2012) o exercício da 
cidadania, porque nele se refletem preocupações transversais à sociedade, enquadra uma dimensão de Educação para o Desenvolvimento sublinhando que a EDvisa a consciencialização e a compreensão das causas dos problemas do desenvolvimento e das desigualdades a nível local e mundial, num contexto de interdependência e globalização, com a finalidade de promover o direito e o dever de todas as pessoas e de todos os povos a participarem e contribuírem para um desenvolvimento integral e sustentável. (DGE, 2012)

A cidadania e a ED cruzam os seus olhares na valorização da dimensão humanizadora e transformadora de atitudes através de uma abordagem crítica e dialógica do processo de aprendizagem que valoriza o saber de todos os cidadãos e estimula a diversidade de formas de compreensão da realidade. A ED partilha com a educação para a cidadania o objetivo da mudança social e da educação para determinados valores, procurando transformar convicções e atitudes. Ambas privilegiam a participação, a construção coletiva e cooperativa do conhecimento e da ação (ENED, 2008). A prática de cidadania e de desenvolvimento constituem um processo participado que envolve todos os cidadãos no apelo à reflexão mas também na ação transformadora sobre os problemas sociais sentidos por todos e por cada um. Este modo de estar na sociedade acentua a interação conjunta, a reflexão ponderada, a tomada de consciência e a intervenção social.

Sendo o exercício da cidadania reconhecido hoje como um direito e um dever de todos e que, como refere Sarmento, "as práticas de cidadania não se desenvolvem de forma inata, são construídas cooperativamente" (2009, p.45), importa atender às oportunidades de intervenção e de implicação na tomada de decisões experienciadas pelas pessoas nos diferentes contextos de vida em que se integram.

Atualmente, as questões da cidadania, assumem uma nova visibilidade, tributária da globalização, das migrações e do consequente acréscimo do contacto com a diferença. No entanto, na consciência desta diversidade podem menosprezar-se as diferenças identitárias e as contextualizações históricas e culturais dos cidadãos.

As questões levantadas permitem identificar a necessidade de construir respostas alternativas e não tradicionais para as questões da cidadania global. Neste sentido, o construcionismo social apresenta-se como uma perspetiva teórica capaz de operar o corte epistemológico com os paradigmas tradicionais, ultrapassando a dualidade entre o local e o global, a individualidade e o coletivo. Emerge a consciência de que a vivência da cidadania deve ser encarada como um processo em permanente (re)construção em que sejam consideradas as especificidades das narrativas pessoais sem negar a importância às meta-narrativas que as enquadram e lhe dão sentido. Perspetiva-se o envolvimento e a responsabilidade de todos nas questões políticas transnacionais e globais, mas também a necessidade de promover a discussão política das questões associadas da cidadania intima. Santos et al. (2010), tendo em conta a perspetiva de
Plummer (2003), referem a cidadania íntima como a necessidade de refletir e construir um discurso público sobre a vida privada, neste sentido todas as esferas de relação privadas estariam incluídas neste conceito, não apenas a sexualidade, mas também as relações de amizade, o casamento e os cuidados com a família, por exemplo.

Conceptualizando a cidadania no contínuo que se pode traçar entre o íntimo e o global, importa salientar também as questões da cidadania global. Nesta perspetiva o projeto de educação cidadã apresenta-se como um projeto de educação para o desenvolvimento, entendido como um processo globalizador de progresso que amplia as possibilidades de bem-estar, equidade e de sucesso das pessoas. Tal pressupõe a preparação das crianças e jovens para se adaptarem melhor às rápidas mudanças de um mundo cada vez mais interdependente, globalizado e menos seguro. Entre os objetivos que cabe destacar numa educação orientada neste sentido estão: favorecer o encontro de diferentes culturas; promover capacidades essenciais para a compreensão de diferenças, de respeito por todos, de trabalho, de realização de escolhas e de tomadas de decisão orientadas para desenvolvimento individual e coletivo. Nesta linha, entende-se, como afirma Rayo, que "a educação para o desenvolvimento promove valores e atitudes relacionadas com a solidariedade e favorece a compreensão sobre desequilíbrios estruturais, a partir de uma perspectiva crítica, emancipadora, caraterizando-se por ser dinâmica, participativa e criativa, orientada para a ação e para a mudança social” (2004, p.143).

Face à complexidade do conceito e abrangência das dimensões associadas à cidadania é fundamental que o seu desenvolvimento acompanhe a vida do ser humano e que, como tal, ocupe um lugar central no seu processo educativo. E, deste modo, é necessário ter em conta que em processos promotores de uma cidadania ativa e aponta-se para uma pedagogia participativa.

Nesta tarefa educativa é importante promover experiências de aprendizagem que permitam desenvolver conhecimentos, competências e atitudes consentâneas com a complexidade dos processos e dinâmicas envolvidas na vivência cidadã.

A compreensão da matriz de aprendizagem da cidadania defendida neste projeto leva-nos à abordagem de dimensões que se prendem com o conhecer, atuar e pensar como cidadão informado, ativo e responsável.

No que se refere a conhecer, e sabendo que as competências de cidadania se inscrevem na ordem do “saber mobilizar" (Le Boterf, 1994), é importante construir saberes que permitam que a pessoa possa pronunciar-se, de forma contextualizada e esclarecida, sobre tópicos fundamentais de cidadania, nomeadamente a respeito da democracia, do poder, da autoridade, da literacia política, dos direitos humanos, da paridade, do ambiente, etc. Implica ainda conhecer valores, princípios éticos e atitudes de cidadania relacionados com os direitos humanos, a paz, a tolerância e a solidariedade, bem como a assunção de uma perspetiva crítica reflexiva sobre os mesmos e a 
colaboração na construção de um mundo mais justo, mais tolerante e mais solidário. Trata-se da (re)construção de significados sobre cidadania e o questionamento sobre os conhecimentos desenvolvidos. Neste processo, importa atender a que, como refere Santos "os conhecimentos de que os cidadãos irão necessitar para compreenderem como uma sociedade particular funciona dependem da construção de significado em que impere a contextualização e a conceptualização por mudança conceptual” (2007, p.178).

O atuar refere-se ao exercício da cidadania num quadro de vida democrática. Tem a ver com a construção de conhecimentos, atitudes, comportamentos e predisposições em situação. Releva a aprendizagem através de experiências concretas de participação ativa e crítica, desenvolvendo um espírito de cidadania. Implica ter em conta os direitos à participação ativa e democrática, bem como usufruir de oportunidades para praticá-la. Nesta linha, importa considerar que se aprende como atuar em cidadania, praticando a autonomia, a participação, a cooperação social e a tomada de decisão(Santos 2007).

A autonomia aprende-se usufruindo de oportunidades de afirmação e escolha, em ambientes ricos em interações sociais que possibilitem que cada um se torne capaz de pensar, sentir e decidir de forma esclarecida. A participação aprende-sepraticando os direitos de agir, pensar, decidir, valorizar, colaborar na elaboração de regras e contribuir para o debate, em ambientes que respeitem os direitos de todos e que conjuguem interesses pessoais com interesses gerais. A cooperação social aprende-sena diversidade cultural, articulando identidade na diversidade e individualidade na solidariedade, em ambientes que promovam a resolução de problemas e que sejam respeitadores de singularidade pessoal e propiciadores da entreajuda. A tomada de decisão aprende-se em contextos que apresentam intencionalidades claras e que possibilitem emitir opiniões e fazer opções.

O pensar como cidadão ativo e responsável pressupõe o desenvolvimento de conhecimentos, capacidades e atitudes que habilitem cada um para desempenhar os papéis e responsabilidades com que se confrontam ou irão confrontar-se. Pressupõe o envolvimento em ações educativas relativas à formação cívica e ética, o desenvolvimento competências de intervenção e do pensar no âmbito cognitivo e axiológico. Releva-se a formação de melhores pensadores, de decisores mais ponderados e cidadãos mais humanistas, mais responsáveis, mais tolerantes e mais democráticos. Estas qualidades exigem, por sua vez, competências de abstração de compreender problemas complexos, bem como a criatividade, a capacidade de associar, negociar, de se entender com os outros e de compreender projetos coletivos. A aprendizagem do pensar aponta, ainda, para o desenvolvimento de capacidades de intervenção social e afetivas, remetendo para o sentido de responsabilidade, solidariedade, tolerância, julgamento crítico e para a tomada de decisões.
Importa considerar que, hoje, uma das mais importantes tarefas das instituições educativas é contribuir para que as crianças e jovens possam realizar escolhas conscientes sobre suas trajetórias pessoais e constituir os seus próprios acervos de valores e conhecimentos. Pretende-se, assim, a transformação dos contextos educativos em comunidades de vida e de aprendizagem em que se aprende ao mesmo tempo que se vive e vive-se ao mesmo tempo que se aprende.

Releva-se a educação para a cidadania ao longo da vida, realçando a relação entre conhecimento e cidadania, o que inevitavelmente incide numa formação que é, ao mesmo tempo teórica e prática, mobilizável em situações reais da vida, quer seja na escola ou fora dela.

\section{Enquadramento metodológico}

O projeto intitula-se "Palavras que viajam com a cidadania: Materiais pedagógicos de apoio a ações de educação para o desenvolvimento" e tem como principal objetivo contribuir para a construção de uma cultura de cidadania ativa em instituições de ensino superior, procurando um desenvolvimento crescente da participação dentro dos princípios de responsabilização dos vários intervenientes.

Pretende-se que o projeto se desenvolva tendo em consideração três dimensões: (I) ao nível da equipa de investigação, (II) ao nível dos formandos/investigadores, (III) ao nível da comunidade.

Ao nível da equipa de investigação os objetivos principais prendem-se com os seguintes aspetos: a pesquisa de referentes teóricos e metodológicos; a supervisão dos processos de desenvolvimento das diferentes fases do projeto; a mediação do processo de construção de materiais pedagógicos e de instrumentos de apoio à educação para o desenvolvimento e a cidadania global; a elaboração de relatórios periódicos de autoavaliação; a criação de condições para a realização da avaliação externa; a apresentação e divulgação dos resultados a nível local, nacional e internacional.

Ao nível dos formandos/investigadores os objetivos direcionam-se para assumir uma atitude reflexiva e crítica sobre as questões da cidadania global e da educação para o desenvolvimento, constituindo-se como agentes de (trans)formação dos contextos no âmbito da promoção de uma cidadania ativa; para colaborar na construção e gestão de materiais pedagógicos adequados à diversidade cultural das crianças com as quais trabalham e para se implicarem na construção de uma cultura de responsabilidade civil da comunidade educativa da instituição de ensino superior em que nos integramos, procurando que se reflita na formação dos cidadãos e no aprofundamento científico em relação às temáticas em que incide este projeto.

Ao nível da comunidade os objetivos são no sentido de capacitar as instituições para serem agentes de educação para o desenvolvimento, de participar na 
avaliação dos materiais produzidos e na sua implementação e de usufruir dos materiais produzidos para o enriquecimento de práticas no decorrer do projeto e posteriormente.

No que concerne aos formandos-investigadores participantes no projeto serão os alunos dos cursos de Mestrado (Educação Pré-escolar, Educação Pré-escolar e Ensino do $1 .^{\circ}$ Ciclo do Ensino Básico, $1 .^{\circ}$ e 2. ${ }^{\circ}$ Ciclos do Ensino Básico, Educação Ambiental e Educação Social), profissionais cooperantes das instituições protocoladas com a Escola Superior de Educação de Bragança (ESEB).

Face ao desafio que este projeto envolve, desenvolveremos uma pesquisa teórica e empírica junto de um contexto de educação ao nível do ensino superior, a partir da qual procuraremos compreender de que modo os formandos-investigadores envolvidos no projeto constroem a sua literacia cidadã. Impõe-se, então, questionar formandos/investigadores sobre as práticas em desenvolvimento nas instituições educativas, sobretudo as que são, de facto, percebidas na sua vivência quotidiana em contexto de estágio, assim como o seu papel e o papel dos outros agentes implicados para a concretização da agenda da humanidade, quando orientada para os valores da cidadania íntima e da cidadania global, da participação, da cooperação, do ambiente e sustentabilidade, das desigualdades sociais, da discriminação, dos direitos humanos, da igualdade de género, diversidade cultural e da paz, entre outros que possam vir a considerar-se igualmente importantes. Os dados que mobilizaremos para a análise dos resultados, e posterior avaliação do projeto, resultam, sobretudo, da implementação de dois inquéritos por questionário realizados nas suas fases inicial e final.

A implementação do projeto está planeada de forma a dar corpo a seis fases consecutivas, mas igualmente integradas e progressivas (vide tabela 1).

Tabela 1. Fases e descrição das ações

\begin{tabular}{|c|c|}
\hline Fases & Descrição das ações \\
\hline $\begin{array}{l}\text { 1. }{ }^{\text {a }} \text { Fase } \\
\text { Sensibilizar o } \\
\text { público-alvo }\end{array}$ & $\begin{array}{l}\text { Sessões de sensibilização através } \\
\text { da apresentação dos objetivos e } \\
\text { metodologia do projeto. }\end{array}$ \\
\hline $\begin{array}{l}2 .^{\mathrm{a}} \text { e } 3 .^{\mathrm{a}} \text { Fases } \\
\text { Capacitar os } \\
\text { formandos }\end{array}$ & $\begin{array}{l}\text { Formação no âmbito das questões } \\
\text { de educação para o } \\
\text { desenvolvimento, cidadania } \\
\text { global, metodologia de trabalho } \\
\text { de projeto. }\end{array}$ \\
\hline $\begin{array}{l}4 .^{\text {a }} \text { Fase } \\
\text { Elaboração de } \\
\text { material }\end{array}$ & $\begin{array}{l}\text { Construção das atividades sobre } \\
\text { temas específicos e para idades } \\
\text { específicas. } \\
\text { Apresentação dos materiais a um } \\
\text { painel de peritos. }\end{array}$ \\
\hline $\begin{array}{l}5 .^{\mathrm{a}} \text { Fase } \\
\text { Implementação }\end{array}$ & $\begin{array}{l}\text { Implementação dos materiais em } \\
\text { escolas do ensino básico e em } \\
\text { instituições pré-escolares. } \\
\text { Recolha de dados para análise. }\end{array}$ \\
\hline 6. ${ }^{\mathrm{a}}$ Fase & Análise dos dados recolhidos. \\
\hline
\end{tabular}

Análise e

avaliação

Avaliação dos resultados.

Apresentação pública dos resultados

Cada uma das fases será avaliada com recurso a metodologias diversas, estando sempre prevista a elaboração de um relatório de autoavaliação pela equipa responsável do projeto e a verificação de um conjunto de indicadores de realização para cada uma dessas fases.

Prevê-se a inscrição de cerca de 50\% dos alunos dos cursos de mestrado e uma posterior desistência inferior a $10 \%$. Quanto às instituições espera-se uma adesão de mais de metade das instituições cooperantes da ESEB.

Os resultados serão analisados em equipa de trabalho pelos investigadores com a participação dos formandos-investigadores envolvidos no projeto. A avaliação dos materiais será feita por peritos e também pelos professores e educadores cooperantes. No final do projeto será feita a sua divulgação junto da comunidade científica assim como da comunidade participante.

Pretende-se que deste trabalho se retirem ilações sustentadas na real (trans)formação das práticas promotoras de uma cidadania ativa em diferentes contextos educativos. Contudo, a equipa reitera a ideia que, mesmo que o resultado seja positivo, tal não significa que não sejam introduzidos aspetos de melhoria e aspetos inovadores na tentativa de o projeto não estagnar após o seu término temporal.

\section{Reflexões emergentes}

Destacam-se linhas de trabalho que se prendem com o desenvolvimento de conhecimentos e atitudes que favoreçam a entreajuda, a cooperação, a participação, o respeito pelos outros, a preservação do meio ambiente e um consumo responsável.

Esta perspetiva vincula-se a um processo de aprendizagem individual e grupal sobre si próprio e sobre a sociedade, no sentido de construção de uma visão aberta sobre o que pode entender-se por desenvolvimento humano. Importa, por isso, que os intervenientes cheguem a compreender esses problemas, aos quais faz eco a comunidade local e internacional, elaborar um juízo crítico a respeito deles, sendo capazes de adotar comportamentos e atitudes baseados numa ética e em valores livremente assumidos.

Neste âmbito, releva-se um enfoque curricular em que a dimensão integradora e interdisciplinar constituem os traços fundamentais. $\mathrm{O}$ desenvolvimento encara-se, assim, como responsabilidade de todos, de modo a favorecer o desenvolvimento de competências intelectuais, metodológicas e socializadoras. Estas competências apoiam-se em saberes específicos relacionados com a educação para os direitos humanos; educação ambiental e desenvolvimento sustentável; educação para a igualdade de género; educação intercultural; educação para a paz; educação para a cidadania global; educação para aprender a viver juntos, educação para a saúde, educação para o consumo e a utilização dos meios de comunicação e informação. 


\section{Referências Bibliográficas}

ENED (2008). Estratégia Nacional de Educação para o Desenvolvimento (2010-2015). http://d3f5055r2rwsy1.cloudfront.net/i mages/cooperacao/estrategia_nacional_ed.pdf.

DGE (2012). Linhas orientadoras de educação para a cidadania. http://www.dge.mec.pt/sites/default/files/ ECidadania/Docs_referencia/educacao_para_cidada nia_linhas_orientadoras_nov2013.pdf.

Le Boterf, G. (1994). De la compétence. Essai sur un attracteur étrange. Paris: Editions d'Organisation.

Rayo, J. T. (2004). Educação em direitos humanos. Rumo a uma perspetiva global (2. ${ }^{\text {a Ed.). Porto }}$ Alegre:

Artmed.
Santos, M. E.V. M. (2007). Cidadania e educação cidadã. Educação. Temas e Problemas, n. $^{\circ}$ 3, 169-192.

Santos, B. S. et al. (2010). Cometi um crime? Representações sobre a (i)legalidade do aborto. Porto: Edições Afrontamento.

Sarmento, T. (2009). As crianças e a cidadania: abordagens participativas em projectos educativos. In T. Sarmento (org), F. I. Ferreira, P. Silva e R. Madeira, Infância, família e comunidade. As crianças como actores sociais (pp.41-68). Porto: Porto Editora. 